\title{
The Effect of Physical Activity on Hypertension on Adults: Meta Analysis
}

\author{
Dyah Mubarokah Ahadiyati'), Didik Gunawan Tamtomo²), Vitri Widyaningsih²) \\ 1)Masters Program in Public Health, Universitas Sebelas Maret \\ ${ }^{2)}$ Faculty of Medicine, Universitas Sebelas Maret
}

\section{ABSTRACT}

Background: Physical activity has an influence on the risk of cardiovascular disease, one of which is hypertension. Physical activity can be used as an alternative or prevention of the increased risk of hypertension. This study aims to analyze the risk factors for hypertension using a meta-analysis.

Subjects and Method: This study is a metaanalysis study. The articles used in this study were obtained from several databases electroniincluding PubMed, Springer Link, ScienceDirect, Elsevier and Google Scoolar. This article was collected for 1 month. The articles included in this study were full text with cross-sectional design, the collection of articles used the PRISMA flow chart.
Results: Low physical activity 1.32 times increased the risk of hypertension compared with moderate/strenuous physical activity $(\mathrm{aOR}=$ $1.34 ; 95 \% \mathrm{CI}=1.06$ to $\left.1.69 ; \mathrm{p}=0.010 ; \mathrm{I}^{2}: 77 \%\right)$ and statistically significant.

Conclusion: Low physical activity increases the risk of hypertension in adults.

Keywords: hypertension, exercise, physical activity.

\section{Correspondence:}

Dyah Mubarokah Ahadiyati. Masters Program in Public Health, Universitas Sebelas Maret. Jl. Ir. Sutami 36A, Surakarta 57126, Central Java. Email:mubarokah.dyah@gmail.com. Mobile: o85747333905.

Cite this as:

Ahadiyati DM, Tamtomo DG, Widyaningsih V (2020). The Effect of Physical Activity on Hypertension on Adults: Meta Analysis. J Epidemiol Public Health. 05(04): 402-409. https://doi.org/10.26911/jepublichealth.2020.05.04.02.

\section{() Journal of Epidemiology and Public Healthis licensed under a Creative Commons} Journal of Epidemiology and Public Healthis licensed under a Crea
Attribution-NonCommercial-ShareAlike 4.o International License.

\section{BACKGROUND}

Technological advances in various countries have resulted in demographic and epidemiological transitions which can be seen from changes in lifestyle and the emergence of the prevalence of non-communicable diseases (PTM). It is estimated that non-communicable diseases cause $73 \%$ of deaths and $60 \%$ of morbidity worldwide (Yonata and Satria, 2017). The World Health Organization (WHO) estimates that deaths from non-communicable diseases will continue to increase worldwide and in 2030 it is estimated that globally, regionally and nationally the proportion of the mortality rate to be $69 \%$ and the death rate to 52 million people per year due to non-communicable diseases et al, 2017).

The epidemic of cardiovascular diseases cause changes in the demographic and socio-economic that affects the lives, eating habits and work habits. These changes have resulted in an increase in the population in the main risk factors, namely hypertension such as mental health disorders, tobacco use, physical activity, obesity and unhealthy eating patterns (Jadhav et al, 2014). Globally, about 17 million deaths per year are due to cardiovascular disease, which represents nearly a third of the total disease (Utomo et al, 2020). One of these cardiovascular diseases is hypertension, which 
shows a mortality rate of $9.4 \%$ of deaths in the world after $51 \%$ of deaths from stroke and $45 \%$ of deaths from heart disease. The highest prevalence of hypertension is in the African region, which is $46 \%$ and the lowest is in the Americas, which is $35 \%$ (Harahap et al, 2018).

Hypertension is a non-communicable disease that has the largest risk factor associated with death and disease burden worldwide (Kim et al, 2016). Hypertension is a health disorder characterized by an increase in systolic blood pressure more than equal to $140 \mathrm{mmHg}$ and diastolic more than equal to $90 \mathrm{mmHg}$ (Fuchs et al, 2011). Hypertension is often referred to as the sillent killer because sufferers often do not feel the signs or symptoms and only find out after checking or checking blood pressure even after the condition is severe and even has damage to organs (Julianti et al, 2016).

Hypertension is the most deadly disease in the world, as many as 1.13 billion people in the world or $29 \%$ of people are affected by hypertension which is estimated to increase to 1.6 billion in 2025 (Wahyudi and Jatmiko, 2020). Hypertension is a clinical condition characterized by an increase in blood pressure which reaches about $46 \%$ of the normal limit (Vale et al, 2018). Hypertension can cause serious health problems, if it cannot be controlled, it will increase and cause dangerous complications (Kusumawardana et al, 2017).

Lifestyle shifts such as eating habits, lack of physical activity are risk factors for increasing degenerative diseases, one of which is hypertension (Indriawati et al, 2020). The increasing number of hypertension in the world can be influenced by two types of risk factors, namely risk factors that can be changed and risk factors that cannot be changed (Setyaningsih et al, 2016). Some factors that cannot be changed include age, gender, race and heredity. While factors that can be changed include obesity, alcohol consumption, smoking, lack of physical activity, unhealthy eating patterns and stress (Ali and Sumardiyono, 2019).

Health behavior change is the best guideline for controlling blood pressure (Lachhiramka \& Patil, 2016). One of the changes in health behavior is lifestyle changes that play a major role in the pathogenesis and high prevalence of hypertension (Savica et al, 2010). Lifestyle changes have a major influence on the risk of hypertension. A healthy lifestyle can be used as an alternative in the prevention or treatment of hypertension. Physical activity is a healthy lifestyle that can be used as an alternative in reducing blood pressure, but not many or less than $2 \%$ of hypertension sufferers and $8 \%$ of healthy people adhere to or adopt some of these healthy lifestyles (Sackner et al, 2019). Physical activity recommended as prevention and treatment of hypertension and show that to someone who is regularly in physical activity have a lower risk to be hypertensive than in someone who does not do physical activity (Gomes et al, 2010).

Physical activity as a lifestyle change in changing health behavior can be used as an alternative to non-pharmacological treatment as well as control or prevention of disease, especially in non-communicable diseases which have various benefits and benefits for preventing and controlling high blood pressure. Physical activity carried out regularly is very beneficial for the health of the heart and blood vessels, on the other hand, less physical activity will be more susceptible to hypertension. Physical activity greatly affects the stability of blood pressure. People who are not active in physical activity tend to have a higher heart rate which triggers the heart muscle to 
work harder, the harder the heart muscle pumps blood, the greater the blood pressure, which causes an increase in blood pressure (Lachhiramka and Patil, 2016). In this study, a meta-analysis study was conducted which aims to determine and identify the effect of physical activity on hypertension in adults.

\section{SUBJECTS AND METHOD}

\section{Study Design}

This was a systematic study and meta-analysis. The articles used in this study were obtained from several electronic databases including PubMed, Springer Link, ScienceDirect, Elsevier and Google Scoolar. This article was collected for 1 month. The keywords used to find the article were as follows: "Hypertension" AND "Physical activity" OR "Exercise", "Hypertensive" OR "Physical activity" OR "Exercise" OR "Cross sectional", "Physical activity" OR "Exercise" AND "Blood pressure", "Physical activity" AND "Hypertension" OR "Blood pressure"OR"Risk Factor".

\section{Inclusion Criteria}

The articles included in this study were full text articles with a cross sectional design. The article discusses risk factors for hypertension in adults. Articles published in English. The research sample was adults aged 20-60, both male and female. The research result data is multivariate. The final results of the study were reported using adjusted odds ratio (aOR).

\section{Exclusion Criteria}

Articles issued in this study were articles with the RCT research design, case-control, quasi-experimental, and research protocols. Articles are not in English, Statistical results are not aOR.

\section{Operational Definition of Variables}

Physical activity is an activity to move the body that require energy to work or a gesture that is planned and structured involves repetitive body movements with the aim of improving fitness.

Hypertension is a condition characterized by high blood pressure with systolic blood pressure that shows $\geq 140 \mathrm{mmHg}$ and diastolic $\geq 90 \mathrm{mmHg}$ or a failure to maintain blood pressure levels below 140/90 mmHg.

\section{Data Analysis}

Analysis were carried out using the Review Manager 5.3 by calculating the effect size and heterogeneity values to determine the combined research model and form the meta-analysis on the Forest plot.

\section{RESULTS}

The process of searching for articles by searching through journal databases can be seen in Figure 1. Figure 2 shows articles published according to the inclusion criteria. There were 5 studies in the Africa (1 Ghana, 2 Nigeria, 1 Kenya, 1 Sudan), 7 studies in the Asia (2 Bangladesh, 2 China, 1 Iran, 1 Nepal, 1 Thailand).

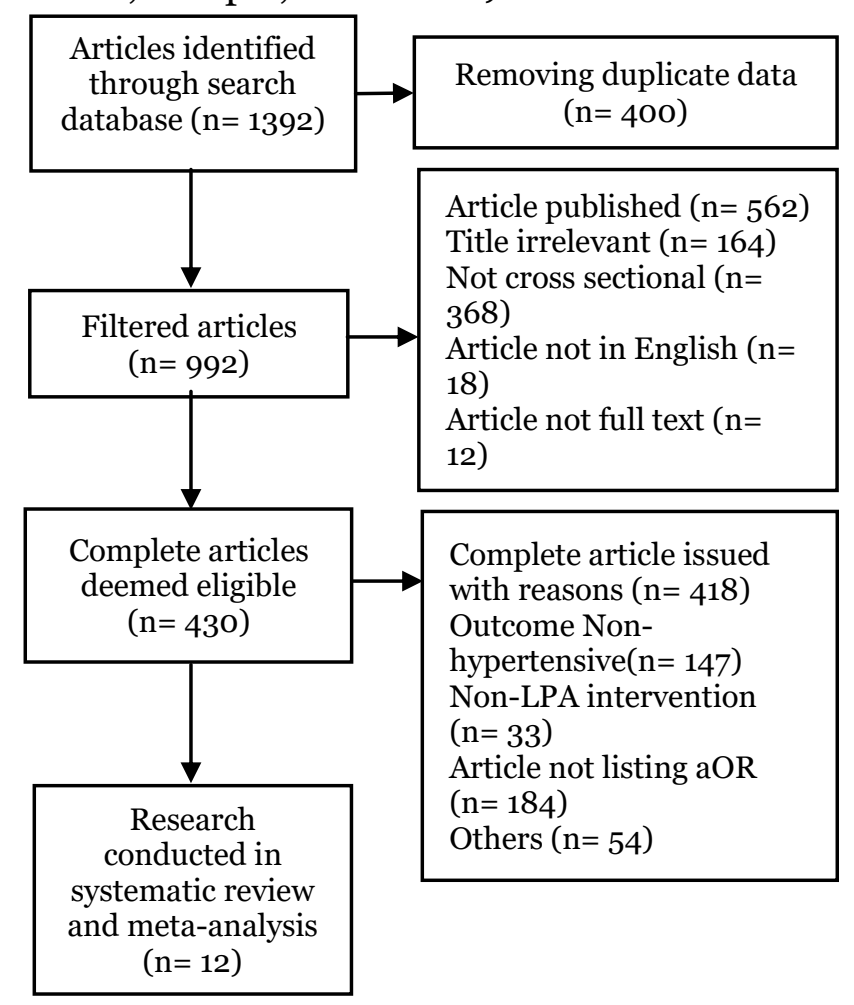

Figure 1. PRISMA flow diagram 


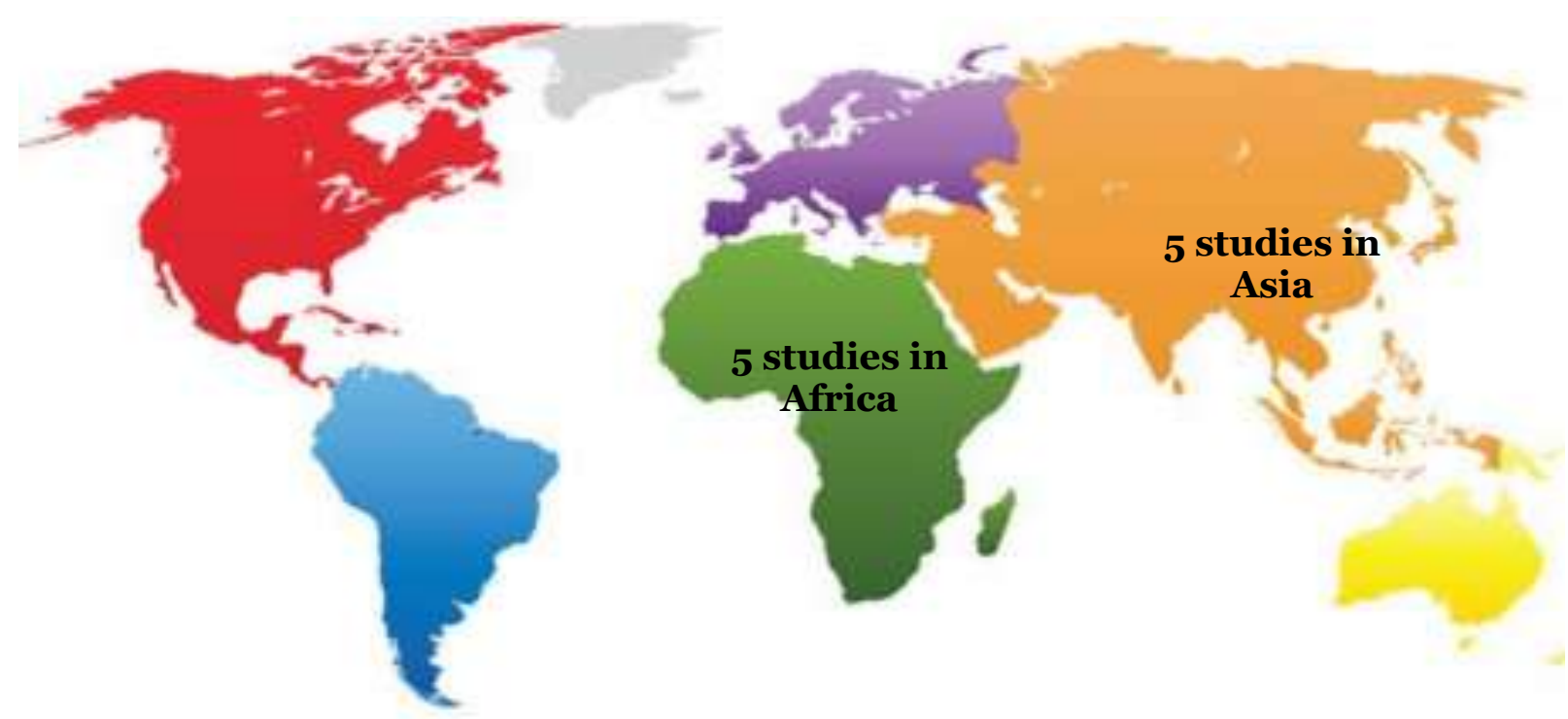

Figure 2. Map of the study areas for meta analysis

A.Physical activity and hypertension

The investigation of articles through several databases found that there were 10 articles of cross sectional study design that had an addjusted odds ratio (aOR). A summary of the 10 source articles is as follows:

Table 1. Summary of the effect of physical activity on hypertension in adults

\begin{tabular}{lcccc}
\hline \multicolumn{1}{c}{ Author (Year) } & Country & Sample & AOR & 95\% CI \\
\hline Amoah et al. (2020) & Ghana & 360 & 5.64 & $2.08-15 \cdot 3$ \\
Awadalla et al. (2018) & Sudan & 323 & 1.91 & $0.99=3.69$ \\
Dhungana et al. (2016) & Nepal & 784 & 12.5 & $4.30-36.3$ \\
Khanam et al. (2019) & Ethiophia & 1,820 & 0.60 & $0.40-0.90$ \\
Li et al. (2017) & Bangladesh & 5,291 & 1.44 & $1.17-1.86$ \\
Mainuddin et al. (2015) & Cina & 9,800 & 1.19 & $0.96-1.48$ \\
Musa et al. (2020) & Nigeria & 455 & 2.55 & $1.35-4.84$ \\
Mirzael et al. (2020) & Iran & 29,965 & 1.20 & $1.07-1.35$ \\
Obarisiagbon et al. (2018) & Nigeria & 354 & 0.57 & $0.24-1.31$ \\
Olack et al. (2015) & Kenya & 1528 & 1.3 & $0.64-2.46$ \\
Somprasong et al. (2020) & Thailand & 1,228 & 2.24 & $1.21-4.15$ \\
Teng et al. (2019) & Cina & 7,010 & 0.99 & $0.87-1.13$ \\
\hline
\end{tabular}

Inclusion criteria: Full paper,design cross sectional, multivariate analysis of adjusted odds ratio (AOR), physical activity intervention, adult subjects.

Based on the results of the forest plot, adults who do low physical activity can increase their risk of hypertension by 1.34 times compared to adults who do moderate /heavy physical activity with statistically significant results $(\mathrm{p}=0.010)$ and $\mathrm{I}^{2}=77 \%$. 
Ahadiyati et al./ The Effect of Physical Activity on Hypertension on Adults

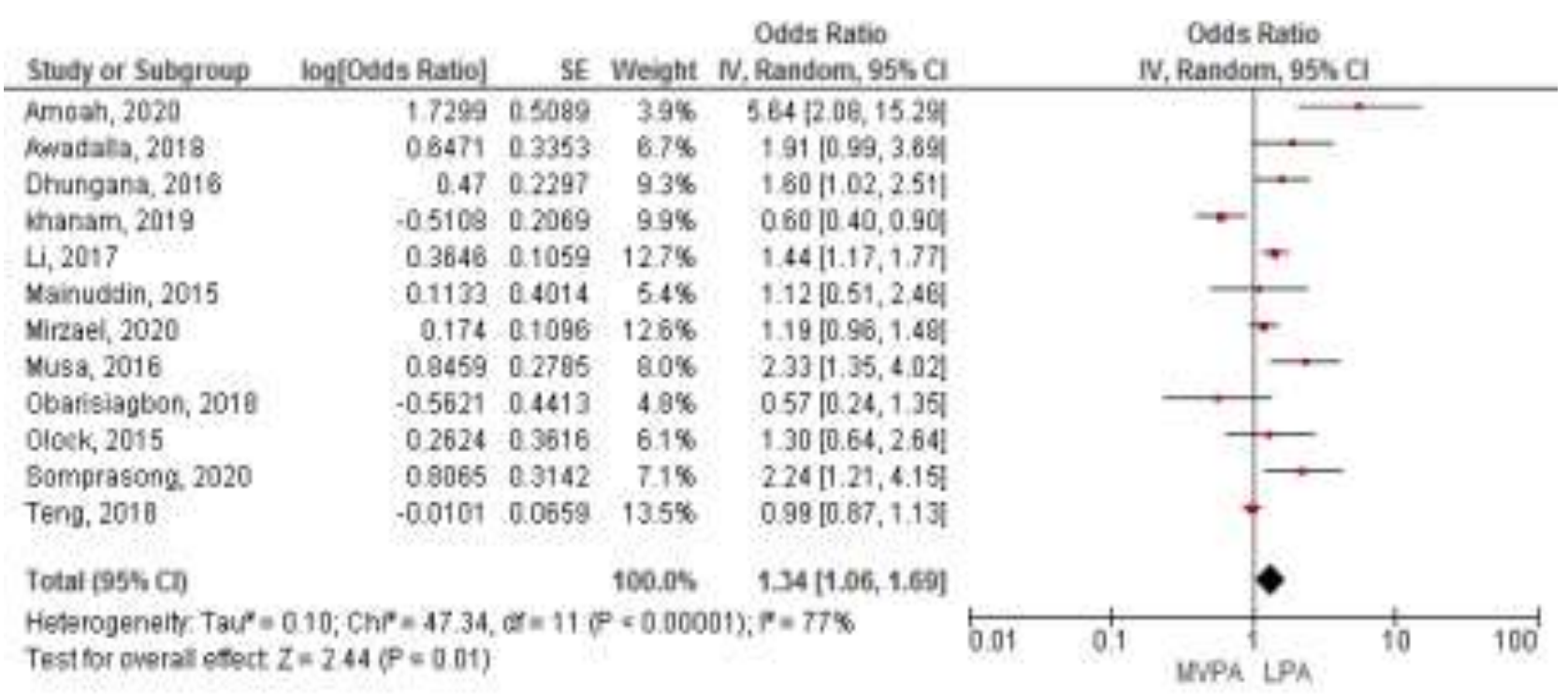

Figure 3. Forest plot of the effect of physical activity on hypertension in adults

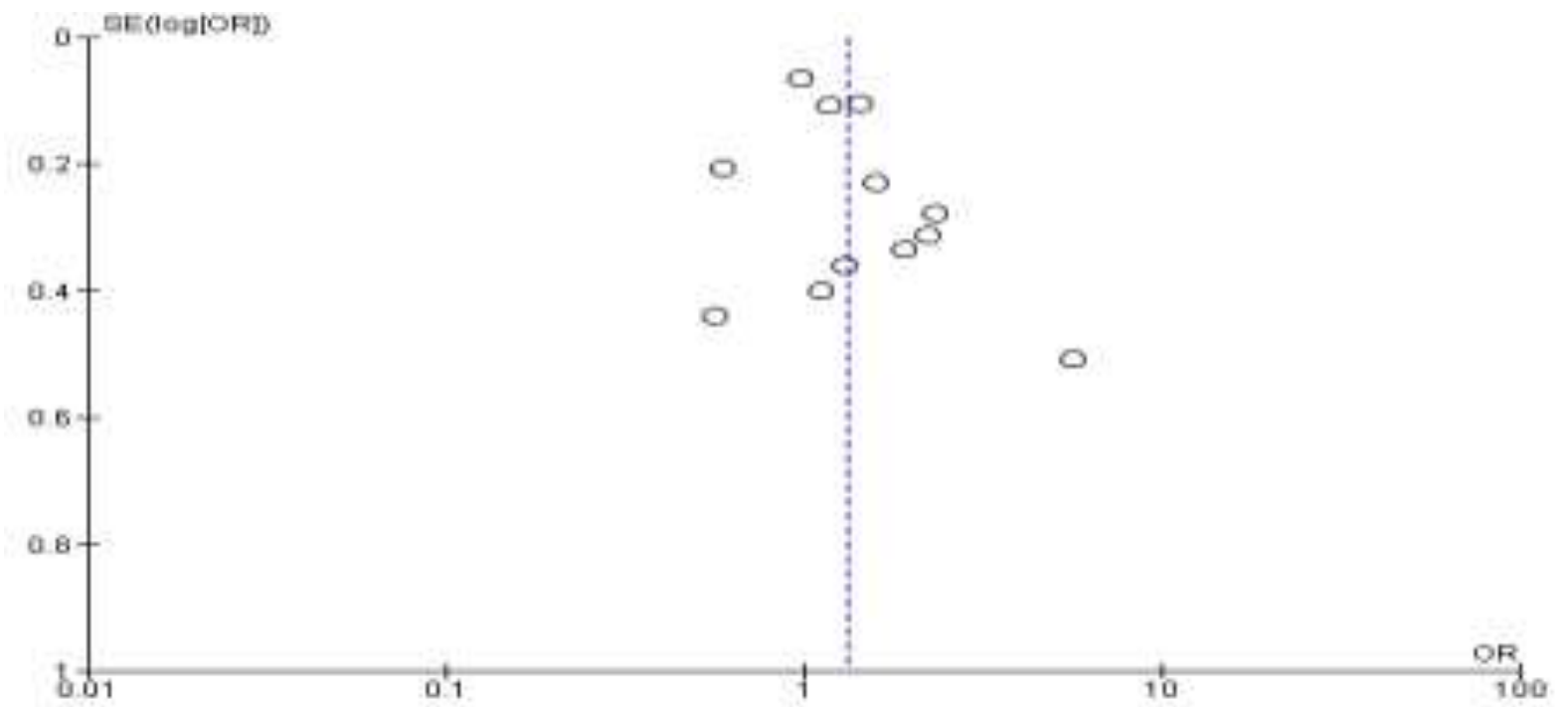

Figure 4. Funnel plot of the effect of physical activity on hypertension in adults

Figure 4. shows no publication bias which is characterized by symmetrical plot right and left where 6 plots are on the right and 6 plots are on the left . The plot on the left of the graph appears to have a standard error between 0 and 0.4 and the plot on the right has a standard error between 0 and 0.4 .

\section{DISCUSSION}

This systematic study and meta-analysis study took the theme of the effect of physical activity on hypertension in adults. The independent variable related to the risk factors analyzed is physical activity in adults, which is important because many still consider it trivial in adult daily life. Most of the statistical results are reported in percentage or crude odds ratio (cOR), whereas studies do not control for confounding factors. Confounding factors that influence the correlation or effect of contamination with a disease predicted by the study are not the same as the actual correlation or effect on the target population. The results of the study are invalid (wrong) (Murti, 2018). 
This systematic study and meta-analysis study use studies controlling for confounding factors. This can be seen in terms of study inclusion. It uses multivariate analysis. The statistical result is aOR. The combined estimation of the correlation of each hypertension risk factor was processed using the RevMan 5.3 application with the general variant inverse method. This method is used to analyze data in the form of rate, time to event, hazard ratio, ordinal scale, adjusted estimation, difference in mean, or mean ratio.

The results of systematic studies and meta-analyzes are presented in the form of forest plots and funnel plots. The forest plot is a graphical representation of the metaanalysis that states several tables and important information including the average score, standard deviation, chance/risk ratio, and the number of study participants (Murti, 2018).

A funnel plot is a plot that illustrates the estimated effect size of each study on the estimated accuracy which is usually standard error. In this case, studies with large or multiple sample sizes and high precision (confidence intervals) will achieve the true effect (Murti, 2018).

The funnel plot can be assessed from research asymmetry by looking at the number of dots on the right and left compared to the standard error and the balance of the number of studies on the right and left (Murti, 2018).

Previous studies have shown hypertension is the cause of $40.6 \%$ of deaths from cardiovascular disease which is associated with unhealthy behavior or lifestyle such as smoking, alcohol consumption and physical inactivity. Physical activity has a direct correlation with the risk of hypertension (Aragaw et al., 2020). Physical inactivity also increases the risk of hypertension in adults aged $\geq 20$ years, compared to adults who regularly perform physical activity (Idris et al., 2020).

The results forest plotshow that adults who do low physical activity are 1.34 times more likely to have hypertension than adults who do moderate/strenuous physical activity. The high prevalence of hypertension is still an important problem in the world, where there is a lack of knowledge or many people who ignore a healthy lifestyle, one of which is doing physical activity. 1.20 times physical inactivity leads to increased prevalence of hypertension (Ding et al., 2020).

\section{AUTHOR CONTRIBUTION}

Dyah Mubarokah Ahadiyati is the main researcher who selects topics, explores and collects research data. Didik Gunawan Tamtomo played a role in analyzing the research data. Vitri Widyaningsih played a role in reviewing the document.

\section{CONFLICT OF INTEREST}

There is no conflict of interest.

\section{FUNDING AND SPONSORSHIP}

This research uses personal funds from the principal investigator.

\section{ACKNOWLEDGEMENT}

We express our best gratitude to providers database electronic PubMed, Elsevier, Springer Link, ScienceDirect, and Google Scoolar

\section{REFERENCE}

Ali B, Sumardiyono S (2019). the relationship between smoking and physical activity with the prevalence of hypertension in Indonesia (analysis of riskesdas data and health profile 2013). Smart Medical Journal, 2(1): 50. https://doi.org/10.13057/smj.v2i1.30 846. 
Ahadiyati et al./ The Effect of Physical Activity on Hypertension on Adults

Dyanneza F, Tamtomo D, Sugiarto (2017). The effectiveness of chronic disease management program in blood pressure control among hypertensive patients. Indones J Med. 02(01): 52-62. https://doi.org/10.26911/theijmed.2016.01.03.06.

Fuchs FD, Fuchs SC, Moreira LB, Gus M, Nóbrega AC, Poli-de-Figueiredo CE, Mion D, et al. (2011). Prevention of hypertension in patients with prehypertension: Protocol for the PREVER-prevention trial. Trials. 12(1): 65 . https://doi.org/10.1186/1745-6215$12-65$.

Harahap RA, Rochadi RK, Sarumpae S (2018). The effect of physical activity on the incidence of hypertension in early adult men (18-40 years) in the Bromo Medan Health Center in 2017. Journal of Muara Sains, Technology, Medicine and Health Sciences. 1(2): 68-73. https://doi.org/10.24912/jmstkik.v1i2.951.

Idris IO, Oguntade AS, Mensah EA, Kitamura N (2020). Prevalence of noncommunicable diseases and their risk factors among residents of IjegunIsheri Osun in Lagos State, Nigeria: a community-based cross-sectional study. BMC Public Health. 20(1):1258 https://doi.org/10.1186/s12889-02009349-2.

Julianti A, Pangastuti R, Noor Y, Ulvie S (2016). Relationship between obesity and physical activity with blood pressure in hypertensive patients. Indonesian Sport Media Media, 5(2), 8-12. https://doi.org/10.15294/miki.v5i2.7878.

Kim JY, Wineinger NE, Steinhubl SR (2016). The influence of wireless self monitoring program on the relationship between patient activation and health behaviors, medication adher- ence, and blood pressure levels in hypertensive patients: a substudy of a randomized controlled trial. J Med Internet Res. 18(6): 1-14. https://doi.org/10.2196/jmir.5429.

Kusumawardana I, Tamtomo D, Sugiarto (2017). Relationship between knowledge and family support regarding hypertension with blood pressure control in elders. Indones $\mathrm{J}$ Med, 02(01): 1-9. https://doi.org/10.26911/theijmed.2017.02.01.01.

Lachhiramka P, Patil S (2016). In patients with hypercholesterolemia. Int J Med Sci Public Health. 5(11): 2249-2251. http://dx.doi.org/10.5455/ijmsph.2016.28032016449.

Murti B (2018). Epidemiological Research Principles and Methods. Karanganyar: Bintang Fajar Offset.

Sackner MA, Patel S, Adams JA (2019). Changes of blood pressure following initiation of physical inactivity and after external addition of pulses to circulation. European Journal of Applied Physiology. 119(1): 201-211. https://doi.org/10.1007/s00421-0184016-7.

Setiyaningsih R, Tamtomo D, Suryani N (2016). Health belief model: Determinants of hypertension prevention behavior in adults at community health center, Sukoharjo, Central Java. J Health Promot Behav. 01(03): 160170. https://doi.org/10.26911/thejhpb.2016.01.03.03.

Utomo P, Djamil M, Suwandono A (2020). Effect of dhikr on blood pressure in pregnant women with hypertension. Indones J Med. 5(1): 87-94. https://doi.org/10.26911/theijmed.2020.05.01.12

Vale AF, Carneiro JA, Jardim PCV, Jardim TV, Steele J, Fisher JP, Gentil P (2018). Acute effects of different resis- 
Ahadiyati et al./ The Effect of Physical Activity on Hypertension on Adults

tance training loads on cardiac autonomic modulation in hypertensive postmenopausal women. J Translational Med. 16(1): 1-9. https://doi.org/10.1186/s12967-018-1615-3.

Wahyudi CT, Jadmiko AW (2020). Family support on the adherence to nutrition intake among adults with primary hypertension in Kalanganyar. 05(02): 132-140. https://doi.org/10.26911/jepublichealth.2020.05.02.01.

Yonata A, Satria APP (2016). Hypertension as a trigger for a stroke. Majority. 5(3): 17. https://juke.kedokteran.unila.ac.id/index.php/majority/article/vi ew/1030. 